\title{
ANAESTHESIA FOR SEPARATION OF CONJOINED TWINS
}

\author{
Louis Fournier, Claude Goulet, \\ Rachel Waugh, and Raynald Chouinard*
}

AT PRESENT there are about 60 recorded operations for separation of conjoined twins. ${ }^{1-7}$ The most famous pair of conjoined twins, the brothers Chang and Eng, were, however, never separated. They were born in Siam in 1811 (and thus the term "Siamese twins"), and immigrated to America in 1829. Their lives seem to have been relatively normal, even to the point of marrying and fathering, respectively, ten and eleven children. During their lives, they considered the possibility of a surgical separation, but the surgeons consulted always refused to undertake the operation.

After their death, which came almost simultaneously when they were 61 years old, an autopsy was done. According to the autopsy report, they were omphalopagus and shared a common liver. ${ }^{8}$ This type of fusion is found the most frequently, but several other combinations occur. ${ }^{3}$

The twins which are best suited for separation are:

1. Thoracopagus twins who are joined by the thorax and often have a common pericardium.

2. Xyphopagus (or omphalopagus) twins who are joined by the abdomen and the lower thorax. Usually there is common liver.

3. Pygopagus twins who are joined by the thighs and often have a common anus. Their vertebral columns may be fused terminally.

4. Ischiopagus twins who are joined linearly by the pelvis. Usually they share parts of the digestive and genito-urinary tracts.

5. Craniopagus twins who are joined by the skull, and often possess common meninges and even parts of the brain.

\section{Case Report}

\section{History}

The conjoined twins which were presented to us for anaesthesia were female and pygopagus. They were born June 2, 1974 in the area of Quebec, by an uncomplicated vaginal delivery. Their 25-year-old mother had previously given birth to a normal infant.

At their birth, the twins were in excellent general condition, despite the incomplete duplication. Their Apgar scores were respectively 7 and 6 . The combined weight of the twins was 4.6 kilograms. They were referred to our hospital at three months of age.

- From Le Centre Hospitalier de l'Université Laval, 2705 boulevard Laurier, Québec, Qué. GIV 4G2. 


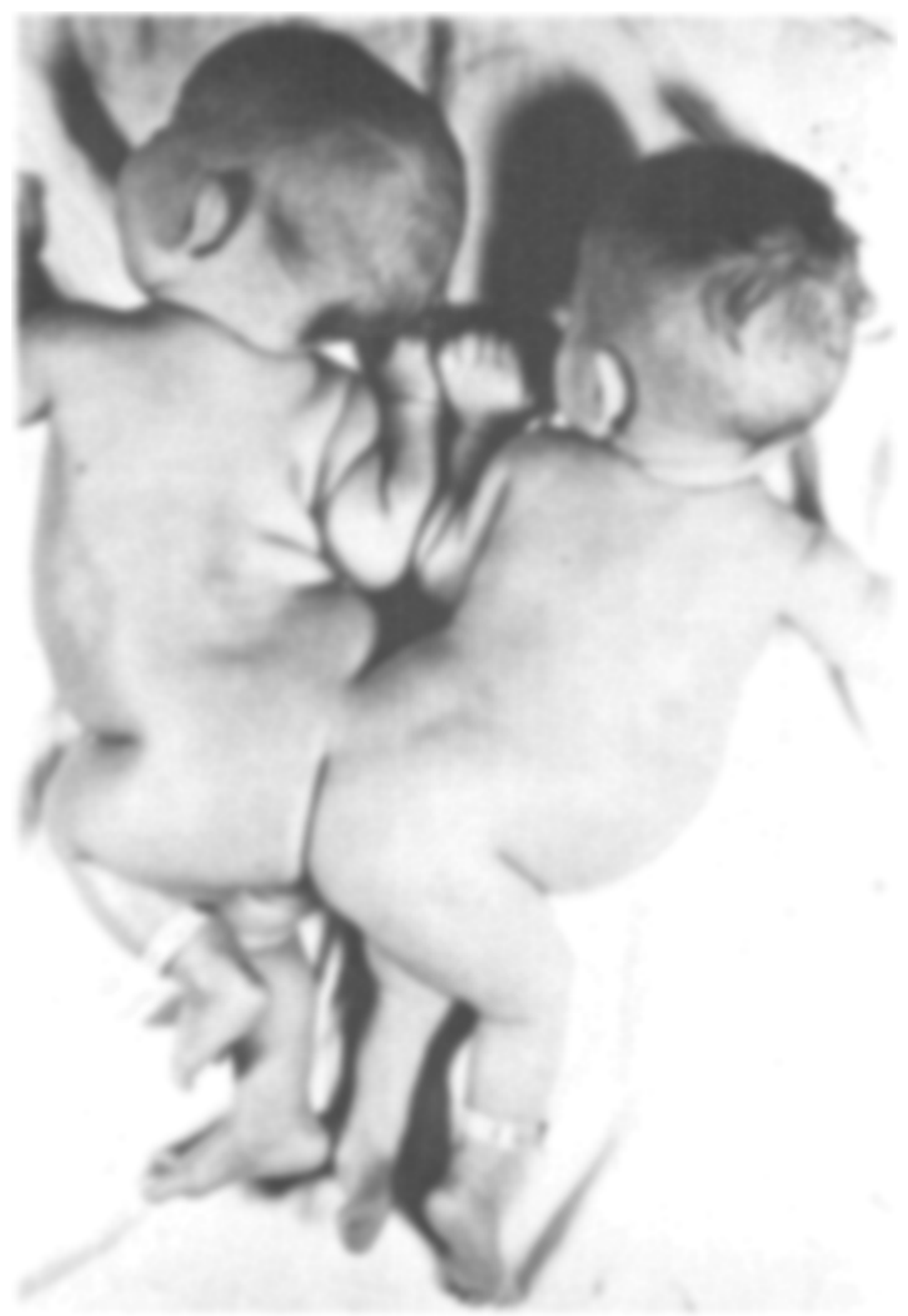

Figure 1.

\section{Examination}

Examination by paediatric and surgical teams revealed that the tiny pygopagus possessed a common anus which belonged to the twin on the left (Josée). (Figures 1-2).

X-rays demonstrated fusion of their terminal vertebral columns with a communication between the two subarachnoid spaces. The two nervous systems seemed nevertheless intact (Figure 3).

The only other anomaly noted was a club-foot belonging to the twin on the right (France) (Figure 1).

It was decided that surgical intervention was indicated and a joint meeting with the Department of Anaesthesia and Surgery was requested to plan the order of procedure. 


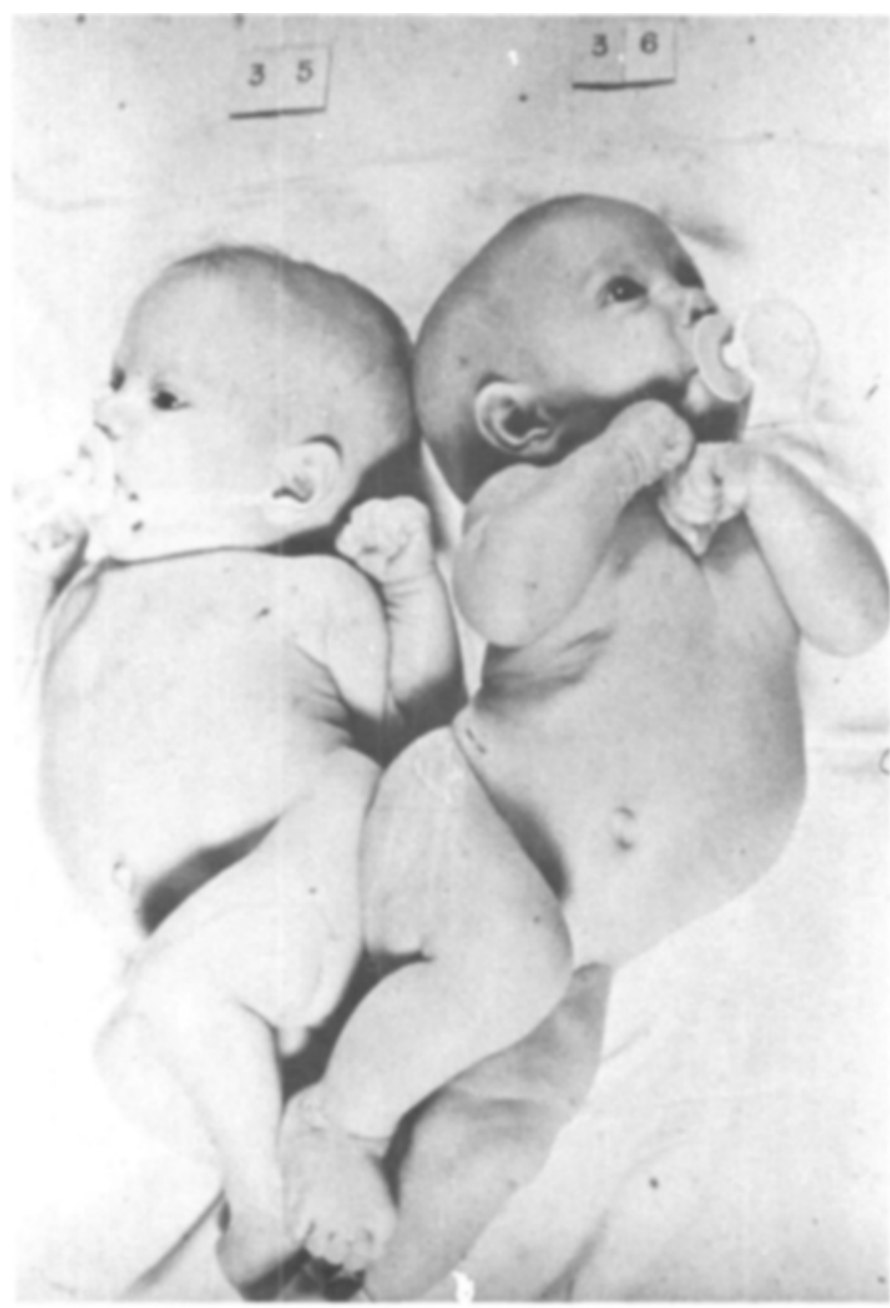

Figure 2.

\section{The Operation}

\section{Planning}

Since the operation was to be performed on the lower intestinal tract and on the nervous system at the same time, it was decided to carry out the separation in two stages. First, a colostomy was done on each twin to permit bowel sterilization prior to the surgical division. The actual separation was to be undertaken at a second stage.

This method of proceeding permitted the anaesthetic team to familiarize themselves gradually with the difficulties to be encountered in this type of anaesthesia. Since the colostomy was a relatively minor procedure, it was possible to test our anaesthetic technique before the actual separation. This was undertaken on 


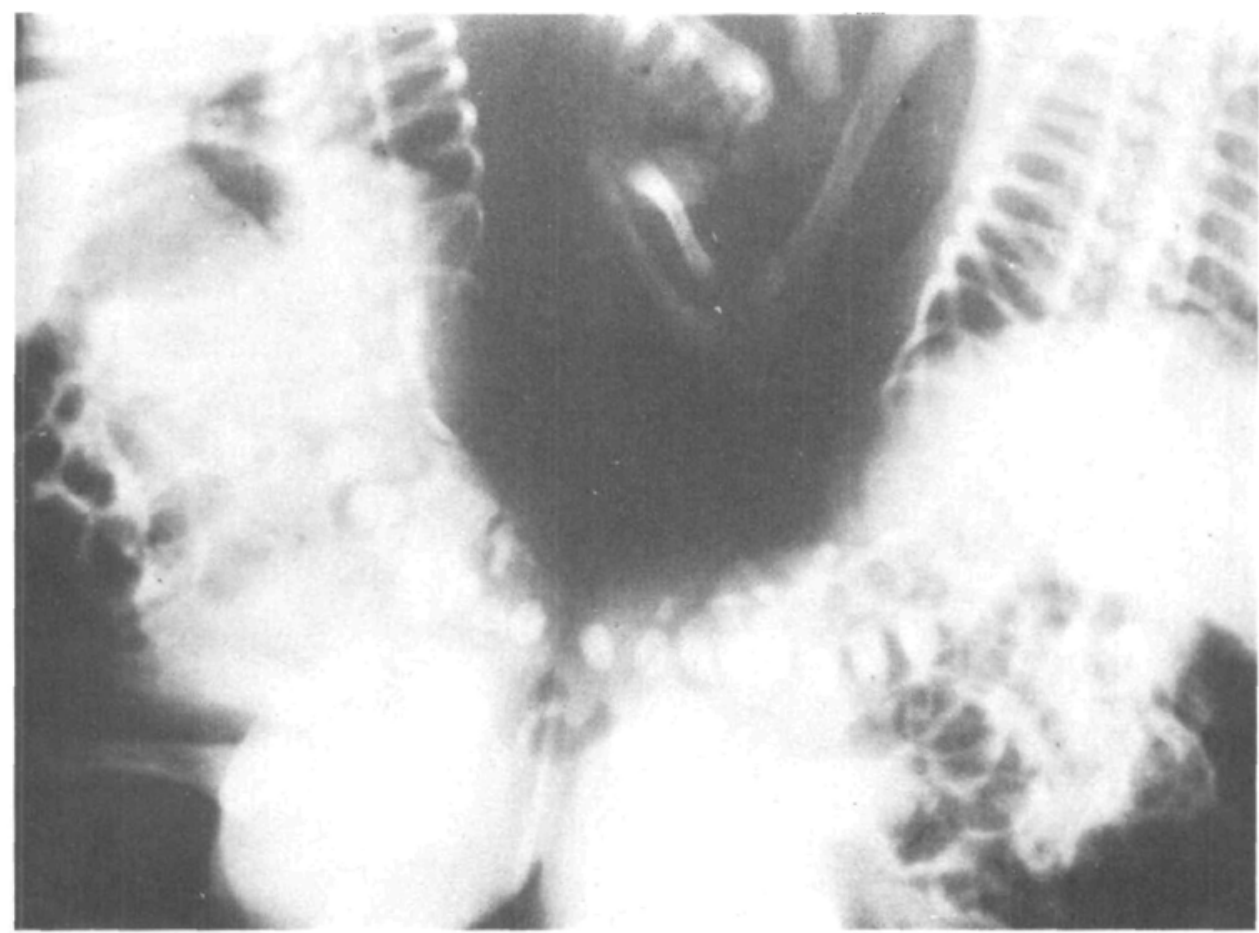

Figure 3.

October 2, 1974. At that time the twins were four months old, and together weighed 9.2 kilograms.

\section{ANAesthetic Technique}

\section{Personnel}

Responsibility for the anaesthesia was assigned to two teams of anaesthetists. Each team consisted of an anaesthetist in charge, a third-year resident, and a nurseanaesthetist.

\section{Anaesthesia}

Anaesthesia was induced first of all in France by mask with equal parts of oxygen and nitrous oxide and 1.5-2\% concentrations of halothane. An oral tracheal tube was easily placed without the use of muscle relaxants. The natural lateral positions adopted by the twins allowed intubation without change of position. The other twin was then anaesthesized and the trachea was intubated using the same technique. General anaesthesia was maintained with the same mixture of oxygen and nitrous oxide supplemented by 0.5 to $1 \%$ halothane as required. No relaxant was used during the procedure, which lasted 10 hours and 15 minutes. Controlled ventilation was used for both babies. An Engstrom respirator was used to control France's ventilation while manual control was employed with Josée. 


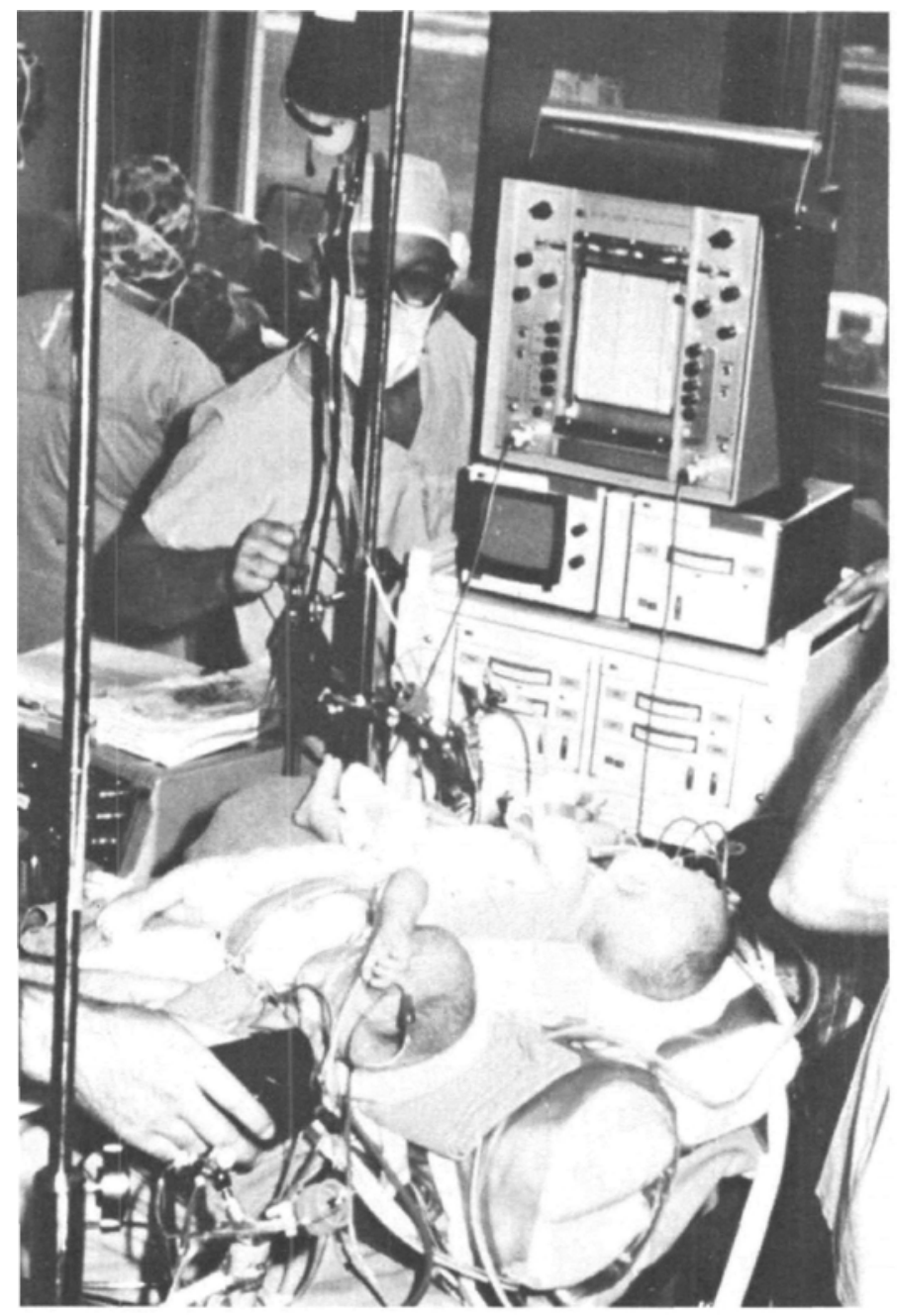

Figure 4.

\section{Monitoring (Figure 4)}

The per-anaesthetic monitoring for separation of conjoined twins does not differ from any major paediatric surgical procedure. The only differences are that with conjoined twins, all equipment must be in duplicate and blood loss is much more difficult to follow: that is, appropriate division of the blood loss between the twins is difficult.

\section{(a) Temperature}

The temperature of each baby was measured using an oesophageal probe, since the rectum was inaccessible. A warming mattress under each twin maintained normothermia. 
(b) Cardiovascular function

To follow cardiovascular function, each twin was fitted with a precordial and an oesophageal stethoscope, three pre-cordial electrocardiogram electrodes, an ultrasonic device for measurement of arterial blood pressure, and a central venous pressure catheter positioned through a venous cut-down. Thus we were able to follow easily all the reactions of the twins to the anaesthetic and surgical manoeuvres.

\section{(c) Blood loss and insensible losses}

The most complete monitoring possible is indispensable for evaluation of the individual blood losses of conjoined twins. Gravimetric evaluation of the blood loss during the separation suggested a total loss of $200 \mathrm{ml}$. This represented 29 per cent of the combined blood volumes of the twins. In order to divide the transfusions appropriately, we were obliged to rely on the monitored parameters as observed for each twin. Thus before separation Josée had received $140 \mathrm{ml}$ while France had received only $80 \mathrm{ml}$.

After separation it was much easier to estimate individual losses. France, who underwent an anoplasty, lost an additional $95 \mathrm{ml}$ which was replaced. Josée, who possessed their common anus, therefore did not need an anoplasty. She lost only $35 \mathrm{ml}$ after the separation, and this was also replaced.

It is noteworthy that in total each twin received $175 \mathrm{ml}$ of blood during the operation, and that an arbitrary division of the blood loss would have given the same result. One must not forget, however, that the timing was very different in the two cases. Josée received most of her transfusion during the separation, whereas France received most of hers after the separation.

To compensate for insensible losses, each twin received, during the operation, 4 to $5 \mathrm{ml}$ of intravenous solution per kilogram of body weight per hour.

\section{(d) Arterial blood gases}

Since we had not judged it necessary to cannulate an artery at induction, we checked the arterial blood gases on two occasions after puncture of the radial arteries.

The $\mathrm{pH}$ and the $\mathrm{Pa}_{\mathrm{O}_{2}}$ were normal. The $\mathrm{Pa}_{\mathrm{CO}_{2}}$ of France, whose lungs were ventilated mechanically, varied between 22 and $28.5 \mathrm{~mm} \mathrm{Hg}$. The $\mathrm{Pa}_{\mathrm{CO}_{2}}$ of Josée whose lungs were ventilated manually stayed at 29.3 to $30 \mathrm{~mm} \mathrm{Hg}$.

\section{Concuusion}

In conclusion it can be said that the separation of conjoined twins presents a challenge to the anaesthetist. We believe, however, that any anaesthetist who works regularly with children is well prepared to face this type of situation.

The principal problems we had to face were the evaluation of the individual blood losses and the congestion of the operating room. The presence in the same operating room of two anaesthetic teams, two surgical teams, cameras and spectators, all surrounding two tiny twins weighing together 9.2 kilogram certainly might be aptly called "congestion." If we add to this impressive entourage all the monitoring equipment connected to the two patients, movement became an impossibility. 
For this reason closure of the wounds was continued after the separation in the same operating room, instead of transferring one twin to another suite, as had been originally envisaged. Despite this decision, or perhaps even because of it, there was no infection post-operatively. Infection was feared because of the simultaneous opening of the spinal canal and the digestive tract during the same procedure.

The twins recuperated well from their adventure and left the hospital December 3,1974 , at the age of six months.

\section{SUMMARY}

We have presented the anaesthetic technique used during the separation of two female pygopagus conjoined twins. The twins were three months old and weighed 9.2 kilograms on the day of the operation. The main problem during the operation was to evaluate blood volume lost by each patient and a close monitoring of all cardiovascular parameters was necessary to attain this aim. The little pygopagus recuperated well and left the hospital at six months old.

\section{RÉSUMÉ}

Nous avons présenté la technique anesthésique utilisée lors de la séparation chirurgicale de deux jumelles siamoises pygopages. Les jumelles étaient âgées de 3 mois et pesaient ensemble 9.2 kilogrammes le jour de l'opération. Le problème principal fut de déterminer pour chaque jumelle sa part des pertes sanguines et une surveillance étroite de tous les paramètres cardiovasculaires est indispensable à cet effet. Les siamoises ont récupéré et ont pu quitter l'hôpital à lâge de six mois.

\section{REFERENCES}

1. Grossman, H.J., Sugar, O., Greely, T.W., \& Sadove, M.S. Surgical Separation in Craniopagus, J.A.M.A. 153 (3): 201-207 (Sept. 19, 1953).

2. Kiesewetren, W.B. Surgery on conjoined (Siamese) twins. Surgery 59: 860 (1966).

3. Bankole, M.A., et al. The conjoined twins of Warri, Nigeria, Arch. Surg. 104: 294 (1972).

4. Simpsons, J.S. Separation of conjoined thoracopagus twins with the report of an additional case. Can. J. Surg. 12: 89 (1969).

5. Oberniedermayr, A., et al. Les jumeaux siamois de Munich. Cah. Coll. Med. Hop. Paris 10: 749 (1969).

6. Mestel, A.L., et al. Ischiopagus tripus conjoined twins: case report of a successful separation. Surgery 69: 75 (1971).

7. De Angelis, R.R., et al. Successful separation of xyphopagus conjoined twins. Ann. Surg. 172: $302(1970)$.

8. Luckнardt, A.B. Report of the autopsy of the Siamese twins together with other interesting information covering their life; sketch of life of Chang and Eng. Surg. Gynec. \& Obst. 72: 116 (1941).

9. Simpsons, J.S., et al. The importance of monitoring during operations on conjoined twins. Canad. Med. Ass. J. 96: 1463 (1967). 